\title{
Políticas públicas de desenvolvimento para o fim do capitalismo
}

Politiques publiques de développement à la fin du capitalisme

Políticas públicas de desarrollo hasta el fin del capitalismo

Public development policies to the end of capitalism

\section{Gabriela Alvarenga Prestes}

\section{(2) OpenEdition}

\section{Journals}

\section{Edição electrónica}

URL: http://journals.openedition.org/espacoeconomia/5606

DOI: $10.4000 /$ espacoeconomia.5606

ISSN: 2317-7837

\section{Editora}

Núcleo de Pesquisa Espaço \& Economia

\section{Refêrencia eletrónica}

Gabriela Alvarenga Prestes, «Políticas públicas de desenvolvimento para o fim do capitalismo », Espaço e Economia [Online], 14 | 2019, posto online no dia 10 agosto 2019, consultado o 06 setembro 2019. URL : http://journals.openedition.org/espacoeconomia/5606 ; DOI : 10.4000/ espacoeconomia.5606

Este documento foi criado de forma automática no dia 6 Setembro 2019.

(c) NUPEE 


\title{
Políticas públicas de desenvolvimento para o fim do capitalismo
}

\author{
Politiques publiques de développement à la fin du capitalisme \\ Políticas públicas de desarrollo hasta el fin del capitalismo \\ Public development policies to the end of capitalism
}

Gabriela Alvarenga Prestes

\section{INTRODUÇÃO}

1 Na situação atual de crise econômica mundial, essa pesquisa contribui para o debate sobre a revisão dos valores sociais assumidos no modo de produção capitalista e alternativas de desenvolvimento.

2 A defesa das ideias aqui expostas se fundamenta, basicamente, a partir das leituras de diversas obras entre autores clássicos e contemporâneos, os quais os principais são Marx e Engels, Mézàros, Harvey, Fernandes, Santos e Bambirra. Suas teorias se encontram aqui costuradas com o objetivo de dar sentido prático à fundamentação teórica e reflexão crítica, ao que diz respeito à elementos e estruturas que envolvem a construção de um modelo de desenvolvimento próprio para América Latina.

3 As teorias que fundamentam essa reflexão, já mencionadas acima, serão associadas a experiências concretas da relação Estado-sociedade-homem-natureza, tendo como objeto de estudo as políticas públicas para cooperativas de produção agrícola em Cuba e no Brasil. No caso do Brasil, especificamente, serão analisados os impactos dessa política pública no MST (Movimento Sem Terra).

4 Foi a partir da análise de cada uma dessas políticas públicas, dos seus respectivos impactos em cada população rural específica, que foi possível a identificação de alguns desafios a serem superados pelo Estado e de fatores que contribuem para a construção de 
"saídas" da lógica de produção capitalista e configuração concreta de uma possível nova conduta político-econômica latino americana.

5 Tendo como metodologia de pesquisa o método materialista dialético, essa pesquisa leva em consideração o processo histórico do capitalismo periférico latino americano e as principais "cicatrizes" geradas pela manifestação das contradições presentes no seu modo de produção e na configuração das relações humanas.

\section{Parte I}

6 De acordo com Flamarion (1986), a identidade mais complexa enquanto sociedade/ civilização nos tempos da América Pré-Colombiana foi o Império Inca.

7 Através de sua pesquisa minuciosa, por meio da consulta à registros arqueológicos, antropológicos, textos de conquistadores cronistas, missionários e funcionários reais, escritores, documentos legais da época da colonização e textos indígenas, o autor afirma que o povo Inca funcionava como uma confederação de regiões tribais.

$8 \mathrm{Ou}$, no caso dos povos que habitam a região que hoje é o Brasil, grupos que vivenciaram outros modelos complexos da organização indígena, descentralizado, o fato é que as relações de produção lhes eram próprias e cooperativas.

9 No entanto, quando consultamos a história, consta-se que esse processo autônomoregional, foi interrompido a partir da época do "Descobrimento do Novo Mundo".

10 Configurado por imposição, caracterizado pela implementação do modelo escravista de produção, a divisão dos territórios da América Latina, assim como o processo de "independência" política para a formação dos Estados latino-americanos, são fatos históricos consequenciais ao da intervenção provocada pelo contato do Velho Mundo com o Novo Mundo.

11 A relação entre Metrópole-Colônia, o saqueamento dos bens naturais e culturais desses lugares, estabeleceu uma forma de inserção subordinada, destes países, na divisão internacional do trabalho.

12 A colonização desses povos determinou um capitalismo conveniente aos colonos. E os paradigmas que constituem a perspectiva de desenvolvimento político e econômico, hoje, séc. XXI, na América Latina, ainda contemplam e se amarram à exigências do capital central, estrangeiro.

13 Sobre a perspectiva dominante de desenvolvimento da humanidade, o capitalismo, enquanto sistema econômico, social e político, se configura, estruturalmente, à base de relações de desigualdade através da (super) exploração do trabalho e controle absoluto de bens naturais vitais do planeta Terra, com a finalidade de acumulação de bens e produção de mais valia (MARX, 1996; MÉSZÀROS 1998; WIM DIERCKXSENS, 2013; HARVEY 2014) .

14 E sobre as consequências atuais desse modo de produção, Wim Dierckxsens (2013), na defesa de sua teoria de "emperro" do capitalismo e de saturação das condições materiais para manutenção de seu movimento de "destruição criadora", destaca que não é somente pelas consequências do mau uso das tecnologias e a produção de consequências como a poluição do ar e das águas, buracos na camada de ozônio, aumento da temperatura e descongelamento dos hemisférios; mas também pela falta de condição de a natureza se recuperar no mesmo tempo em que sofre exploração dos humanos. 

SANTOS, 2012) uma das "consequências-sequelas" da relação histórica dialética entre e intra ex-metrópoles e ex-colônias, subdesenvolvimento-desenvolvimento, no que diz respeito especificamente à América Latina, é a não formação de uma classe burguesa autônoma. Que, por sua vez, ao ocupar um lugar de sócio menor na divisão do capital internacional, transformam os Estados latino americanos em instrumentos exploradores de sua população, subservientes aos interesses estrangeiros e, legitima, através de instituições ditas democráticas, relações fascistas para com a sociedade (FERNANDES, 2015).

Dessa maneira, essa burguesia/elite local mantém um comportamento de estado permanente contra revolucionário, resistente a mudanças e cria instrumentos de manutenção de seu poder político e econômico, dentro e fora do Estado.

No decorrer dos estudos sobre as condições socioeconômicas e políticas da América Latina, existem duas perspectivas: uma clássica e conservadora, representada pela Comissão Econômica para a América Latina (CEPAL), e autores como Faletto e Cardoso (2000 [1973]) na qual a ideia de "desenvolvimento" tem como principal resultado a superação de índices econômicos mundiais e que, portanto, compartilha com a perspectiva estruturalista e etapista das economias subdesenvolvidas para integração dessas ao mercado internacional; e a Teoria Marxista da Dependência (TMD) representada por um grupo de intelectuais como Bambirra (1974), Marini (1986 e 2012), Theotônio dos Santos (2012) e Luce (2018) que defendem, a partir da Teoria do Valor-Trabalho de Marx, que desenvolvimento e subdesenvolvimento são processos vinculados e resultados de desenvolvimento totalitário e dialético do capitalismo no mundo. E que o fator de grau de desenvolvimento da indústria nacional sem o devido rompimento com as economias dominantes, de nada mudaria o aspecto dependente da América Latina, apenas modificaria suas expressões.

18 Para autores "cepalinos", a superação do subdesenvolvimento da América Latina é uma questão de aprimoramento das políticas econômicas, de aproximação ao capital estrangeiro para investimentos internos no processo de industrialização, construção civil, urbanização e "modernidade" dos países periféricos.

19 Já para os autores da TMD as relações entre o centro do capitalismo e a periferia são relações que estão inseridas na dinâmica da produção de capital e que, portanto, emergem contradições a partir de elementos inerentes ao seu metabolismo. Defende que a condição de dependência e subdesenvolvimento não é superável meramente através de políticas econômicas de desenvolvimento elaboradas a partir de pressupostos liberais, os quais têm como resultado a reprodução de um modo de produção e de organização das relações de trabalho/sociais numa perspectiva individualista e alienante à criação coletiva para prática humanitária e sustentável.

\section{Parte II}

Como já apontado por Marx em O Capital (1996), as contradições necessárias para realização do capital, geram crises cíclicas no capitalismo. Harvey, em sua obra as 17 contradições e o fim do capitalismo (2014) destrincha essas contradições e as classifica entre estruturais, mutáveis e perigosas. 
21 O autor contemporâneo afirma que, como saída historicamente e concretamente percorrida, o sistema socialista, ao tentar dissolver algumas dessas contradições, criou suas próprias num sistema de dependência com o capitalismo e que o socialismo precisa, também, ser repensado. Compreende o Estado como organismo originado e necessário ao capital e o capitalismo e por isso joga a responsabilidade da "saída" possível para a organização da sociedade civil em "associações populares".

22 E ao tratar das ideias - que, inicialmente, confesso, as julguei como insuficientes do ponto de vista de serem ideias para a prática, Harvey recorre frequentemente ao termo “associações populares" e nem sequer menciona o Estado como possível ativista de uma de suas sugestões.

23 Apesar do autor não falar de cooperativismo ou atribuir à configuração dessas “associações populares" uma espécie de ampliação da doutrina cooperativista para a organização econômica e política da humanidade, destaco, a seguir, como essa doutrina dialoga diretamente com suas propostas.

\section{Breve histórico do cooperativismo no mundo e a formação da doutrina cooperativista}

24 Em perspectiva histórica, o cooperativismo surgiu como reação ao intenso processo de mecanização do trabalho a partir da década de 1750. A primeira cooperativa formalmente reconhecida é a Sociedade Rochdale dos Pioneiros Equitativos em 1844, na Inglaterra, cidade de Rochdale, hoje um bairro de Manchester.

25 Em 1895, após a expansão mundial do cooperativismo, criou-se a Aliança Cooperativa Internacional (ACI) com sede atual na Bélgica, em Bruxelas. Com a missão de "representar, congregar e defender o movimento, divulgar a doutrina e preservar seus valores e princípios" " a ACI conta com mais de 230 organizações entre seus membros, mais de 100 países, que representam mais de 1 bilhão de pessoas de todo o mundo ${ }^{2}$.

Compreendido como organização que afasta as figuras do patrão, o empregado e o intermediário, assegurando aos cooperados a propriedade dos instrumentos de produção e a participação nos resultados do empreendimento, é caracterizado como modo de produção anticapitalista.

27 Assim, interpretado como alternativa para o desenvolvimento local e diminuição da desigualdade social, do ponto de vista filosófico, o cooperativismo surgiu embasado em valores universais, de união, colaboração, cooperação, pregando uma mentalidade de valores comunitários na produção de interesses comuns. Do ponto de vista social e político, o sistema de autogestão de cooperativas muitas vezes proporciona sentido de autonomia na organização coletiva de meios de produção e sobrevivência, assim como a politização da classe, produtora local.

28 O cooperativismo é regido por sete princípios:

$29 \quad 1^{\circ}$ - Adesão voluntária e livre

30 Qualquer pessoa que quiser, pode participar deste modelo de trabalho. Ele serve para todos, desde que a adesão seja feita por conta própria.

$31 \quad 2^{\circ}$ - Gestão democrática 

visam o desenvolvimento da comunidade da qual fazem parte. Seja por meio da geração de empregos, por oferecer produtos e serviços com preços mais em conta (já que não se prioriza o lucro) ou mesmo incentivando pessoas ${ }^{3}$.

43 A Doutrina Cooperativista é materializada no Ato Cooperativo. Ou seja, significa que um grupo de indivíduos decidiu se reunir para produção de bens e serviços de impacto direto na sociedade a qual pertence. Orientada para um fim social, o cooperativismo propõe o exercício da solidariedade econômica, atribuindo ao ato de fazer, ou seja, ao trabalho, o eixo, a engrenagem de sua estrutura. Destitui a centralidade da reprodução de capital, da qual a empresa privada com fins lucrativos tem como objetivo principal.

44 Existem vários ramos do cooperativismo: agropecuário, de consumo, de crédito, educacional, habitacional, de infra-estrutura, mineral, de produção, saúde, trabalho, transporte, turismo e lazer. Conforme a modalidade, os modelos de consumo se diversificam: "os de crédito, com finalidade de promover a poupança e financiar empreendimentos dos associados; e os habitacionais, que se destinam à construção de conjuntos residenciais para seus cooperados" (SOUSA, p. 2, 2009).

45 Palmyios P. Carneiro afirma que

o essencial na educação cooperativista é fazer o cooperado- usuário compreender que o consumo dever ser colocado sob as regras da produção a serviço do homem, e que o único método de aplicar esses conceitos econômicos é através da participação existencial-social, esteja essa participação intrínseca ao próprio trabalho, ao ato de gerir, de poder e de arbitrar (CARNEIRO apud CABRAL, 2010, p. 9). 
O fato de as cooperativas serem organizações econômicas sem fins lucrativos dá suporte filosófico ao valor funcional-social, com a prática na qual o trabalho humano é a finalidade. "Empresas são organizações de capital que utilizam as pessoas. Cooperativas são organizações de pessoas que utilizam o capital (...). Pois a meta é sempre a preservação do homem pelo seu restabelecimento conforme sua função social" (CABRAL, p. 4 e 5 [grifos nossos], 2010).

47 Existente em realidades antagônicas, capitalista e socialista, o cooperativismo se revela um objeto curioso. Compreendido como organização contra-hegemônica por não ter fins lucrativos e a divisão do trabalho se organizar horizontalmente, a seguir destaco dois casos concretos de políticas públicas para cooperativas e uma breve análise sobre o desenvolvimento da lógica cooperativista para produção agrícola, nos contextos específicos de Cuba e Brasil.

\section{Cooperativismo em Cuba}

48 Antes sob o comandado do presidente Fulgencio Batista, influenciado pelos Estados Unidos, Cuba é um país socialista desde 1959, ano de sua Revolução, liderada por Fidel Castro, Ernesto Che Guevara, Raul Castro, Camilo Cienfuegos e Juan Almeida Bosque.

49 Assim que assumiu o socialismo enquanto sistema político e econômico, Cuba se mantinha com o apoio de parceiros políticos e ideológicos, Rússia e China, principalmente.

50 Nessa época, as Cooperativas de Créditos e Serviços (CCS), já existentes, foram as primeiras experiências que serviram de exemplo para a organização de novas associações de produção. Formadas por camponeses beneficiados com a Reforma Agrária, ocorrida logo após a Revolução, as terras têm natureza privada e o cooperativado tem facilidade no acesso a insumos para produção através de políticas de crédito e comercialização de produtos (HARNECKER, 2012 [grifos nossos]).

51 Em 1975, no Primeiro Congresso do Partido Comunista Cubano, declarou-se o incentivo a promoção de Cooperativas de Produção Agrícola (CPA), as quais também foram integradas por camponeses beneficiados pela Reforma Agrária, mas que vendem suas terras para a formação das cooperativas, atribuindo-as uso coletivo. Ainda ativas, são controladas diretamente pelo Estado e subordinadas à instituições estatais, como o Instituto Nacional de la Reforma Agrária (INRA) e a Associación Nacional de Agricultores Pequeños (ANAP) (Ibid).

52 Em 1982 aprova-se a Lei das Cooperativas Agropecuárias. Nessa mesma década houve a experiência das cooperativas de segundo grau, as quais se integraram territorialmente às cooperativas agrícolas, chamadas de Unión Municipal de Cooperativas Agrícolas (UMCA), mas estas duraram pouco tempo (Ibid).

53 Nos anos de 1990, o país enfrentou o Período Especial, havendo a necessidade de produção em todos os ramos da economia nacional com menos insumos. $O$ fim da União Soviética, a qual oferecia suporte tecnológico e industrial para a ilha socialista, foi seguido do Bloqueio Econômico imposto pelos Estados Unidos da América do Norte. $\mathrm{O}$ isolacionismo obrigatório impossibilitou a criação de parcerias e acordos econômicos com outras nações.

54 Como estratégia de manutenção do pleno emprego, em 1993, surgiram, como subdivisões das empresas estatais, as Unidades Básicas de Produção Cooperativa (UBPC). Diretamente 
vinculadas e direcionadas às necessidades de empresas estatais, contam menos ainda com a possibilidade de autonomia na gestão de sua produção, mas também na comercialização de seus produtos e serviços. Caracterizadas como uma combinação híbrida entre os outros dois tipos de cooperativas já mencionadas são usufruídas coletivamente e tem os meios de produção comprados do Estado (Ibid).

A partir das tensões geopolíticas estabelecidas pós-Guerra Fria e globalização das relações econômicas, Cuba começa a desenvolver políticas estratégicas para superação das dificuldades econômicas e manutenção de seu modelo de Estado e sociedade. Em convergência com a agenda internacional da Organização das Nações Unidas (ONU) e da OIT a partir dos anos 2000, assume o compromisso com o ecodesenvolvimento como lógica motriz para políticas públicas adequadas às suas possibilidades de desenvolvimento econômico e preservação da humanização do trabalho (BOTELLO, DELGADO e POZO, 2010).

56 No entanto, de acordo com pesquisas, no caso das CPAs (Cooperativas de Produção Agrícola), pontua-se que o princípio da Autogestão não é praticado devido ao vínculo de dependência com o Estado. De acordo com as pesquisas realizadas por Camila Piñeros Harnecker (2012), esse é o maior desafio da elaboração de políticas públicas para cooperativas em Cuba, caracterizado pela tradição da centralidade dos processos de decisão no âmbito estatal.

\section{Cooperativismo no Brasil}

57 No Brasil, o cooperativismo surgiu em 1889, em Minas Gerais. A pioneira foi a Sociedade Cooperativa Econômica dos Funcionários Públicos de Ouro Preto. Conforme o modelo de organização foi se desenvolvendo no país, o setor agropecuário foi assumindo destaque na região no Sul. Antes disso, as cooperativas se mantinham concentradas no consumo, como incialmente na Inglaterra (MAPA, 2006, p. 16).

O primeiro incentivo dado pelo poder público às cooperativas foi realizado pelo governador João Pinheiro por volta de 1910, em Minas Gerais, na organização do comércio cafeeiro. Portanto, o marco das políticas públicas para cooperativas aqui no Brasil é o início do século $\mathrm{XX}$, período no qual podemos destacar a influência do pensamento político dos imigrantes europeus (Ibidem).

59 O desenvolvimento do cooperativismo no Brasil tem como desafio a manutenção dos princípios de sua Doutrina numa sociedade e Estado que se constituiu, historicamente, através da transposição de valores de ordem liberal, durante a colonização e exploração massiva dos territórios e povos locais.

60 Nesse contexto, uma das características e reflexos da relação de dependência desigual e combinada (FRANK, 1996) nessa sociedade e Estado, classificados como subdesenvolvidos, é a desigualdade social que dá condições a materialização de uma população que serve de mão de obra barata para o capital estrangeiro, que apresenta alto índice do trabalho informal e de um Estado que não amplia e até mesmo negligencia a importância do sistema de previdência e proteção social dos seus cidadãos, ou seja, um processo de fascistização do Estado (FERNANDES, 2015).

61 Segundo Sousa (2009), em sociedades capitalistas, o cooperativismo geralmente, surge como "reação a uma situação econômica desfavorável ao trabalhador que, não conseguindo vender sua força de trabalho, ou insatisfeito com a realidade dentro das 
empresas, resolve se unir a outros para que adquiram o capital e os meios de produção necessários para prestar serviço diretamente só consumidor".

Mas de acordo com diversas pesquisas, uma das principais dificuldades de o cooperativismo se materializar genuinamente em sociedades capitalistas, é uma questão cultural e educativa ${ }^{4}$. Pois, retido à prática histórica mercantil liberal, a conduta, a ética $\mathrm{e}$ a moral implantada pelo modo de produção hegemônico, implica na reprodução de indivíduos que não se comprometem na prática dos princípios pontuados na Doutrina do Cooperativismo, pela Aliança Cooperativa Interncaionl (ACI).

63 O principal dilema é o comprometimento com a participação democrática, onde o exercício da decisão coletiva garante a estruturação de uma nova conduta e o assentamento de percepções individuais ampliadas. Uma pesquisa realizada por Demo (1988, p.50 apud SOUSA, p. 6, 2009), informa que é comum o não comparecimento de mais de $50 \%$ dos associados nas reuniões deliberativas. Assim como o caráter voluntário da adesão, já que se consta a expansão do número de cooperativas em períodos de crise econômica. Ou seja, as cooperativas são organizadas conforme a necessidade financeira e por escolha autônoma e solidária.

64 Uma publicação da OIT em 2001, sobre as mudanças, oportunidades e desafios do cooperativismo no Brasil, chama atenção para consequências alarmantes sobre a desvirtuação de cooperativas no país, consideradas pela entidade internacional como falsas.

65 A OIT identifica esse fenômeno como consequente não só da desigualdade social, mas também das leis trabalhistas brasileiras que regulam impostos muito altos para a manutenção do trabalho formal e que, portanto, estariam surgindo cooperativas corrompidas na tentativa de se beneficiarem da redução de certos tributos trabalhistas direcionados para essa categoria de organização (OIT, 2001, p. 9).

Mesmo com essas questões e desafios da manutenção e integridade do cooperativismo num país historicamente liberal como o Brasil, destaca-se também, a partir dos anos de 2000, a presença significativa de cooperativas de habitação e, posteriormente, a partir de 2009, sua inclusão em políticas públicas de habitação no programa Minha Casa Minha Vida - Entidades (União por Moradia Popular-RJ).

67 Durante o governo do Partido dos Trabalhadores (PT) iniciado em 2003, a legislação para cooperativas é revisada e reorganizada com a intenção de valorizar e facilitar a constituição de organizações desse tipo. Uma das consequências, portanto, foi a conquista da inclusão das mesmas em arranjos de parceria em determinadas políticas públicas, como a de habitação pontuada acima.

\section{No Movimento Sem Terra (MST)}

68 Após o processo de "redemocratização" no Brasil, o MST apresentou uma forma de organização dividida em estâncias, como meio de facilitar a ordenação produtiva de forma homogênea nos assentamentos. Essa configuração viabilizou o projeto de cooperação agrícola do MST, sendo o cooperativismo a doutrina e modelo organizacional da produção agrícola do Movimento, e teve como consequência a inserção dos integrantes assentados no mercado de trabalho de forma unificada (BORGES, 2009, p. 4).

69 Antes disso os assentamentos se organizavam aleatoriamente, com a produção diversificada, de acordo com as particularidades em que estavam inseridos. 
70 Segundo Juliano Luís Borges (2009), essa configuração de organização do Movimento foi estimulada pelo contexto social brasileiro pós Ditadura Militar e Governo Collor, em que o Neoliberalismo toma forma e força no nosso país subdesenvolvido. Sobre isso, o MST se manifesta no Jornal dos Trabalhadores Rurais na passagem a seguir:

Diante de uma política econômica agrícola que penaliza o pequeno agricultor, o assentado não pode se contentar com a conquista de um pedaço de terra. Há a necessidade de encontrar meios que lhe possibilite ter acesso a recursos financeiros e técnicos, condições favoráveis de produção e comercialização; acesso á técnicas de produção mais desenvolvidas e a mecanização.(..) Somente assim estaremos aptos a fazer frente a essa acelerada política entreguista do presidente Collor, subserviente aos interesses internacionais aos latifundiários, cada vez mais protegidos por aparatos repressores (JST, 1991, p. 02 apud BORGES, 2009, p. 5).

71 O cooperativismo, enquanto modelo organizacional e jurídico do MST foi e, em alguns casos ainda é, caracterizado por uma produção agrícola em larga escala, envolvendo a mecanização agrícola, a utilização de insumos químicos e divisão do trabalho hierárquica. Mas essas contradições não duraram por muito tempo em alguns assentamentos.

72 A partir do Governo Lula, um processo de autocrítica começa a surgir entre os líderes do movimento. A questão era que esse modelo, no contexto capitalista brasileiro, dialogava diretamente com a o modelo de produção do agronegócio, baseada em relações de produção e de mercado de larga escala.

73 Os camponeses tradicionais, integrantes do movimento, se posicionaram resistentes à lógica de produção imposta, que além de romper com uma ética ideológica socialista defendida pelo movimento a favor da Reforma Agrária, não contemplava a sabedoria campesina tradicional.

74 Além disso, “As contradições da matriz tecnológica modernizante prejudicaram economicamente os assentados, que estavam vulneráveis à instabilidade do mercado e ao endividamento nas fontes financiadoras, entre outros fatores." (Idem, p. 12).

75 Dessa maneira, após um processo de debate interno entre as esferas, assumiu-se a agroecologia como modelo de produção das técnicas operacionais de cultivo, mas manteve-se o cooperativismo para formatação organizacional e jurídica.

76 Associando as técnicas agroecológicas de cultivo e a doutrina cooperativista como princípio organizacional, o MST, atualmente é considerado o maior produtor de arroz orgânico da América Latina ${ }^{5}$. Esse resultado nada mais é do que produto da luta ideológica defendida pelo movimento e sua viabilização prática na proposição de construir uma sociedade que luta por igualdade e direitos humanos.

\section{Algumas conclusões:}

As crises abalam profundamente nossas concepções de mundo e do lugar que ocupamos nele. E nós, como participantes e habitantes inquietos desse mundo que vem surgindo, temos de nos adaptar, por coerção ou consentimento, a um novo estado de coisas, ao mesmo tempo que, por meio de nossas ações e do modo como pensamos e nos comportamos, damos nossa contribuição às pequenas complicações desse mundo (HARVEY, 2014, p. 10).

77 Harvey chama a atenção, nesse trecho destacado acima, a nossa "mea culpa" como integrantes do sistema e absorção de certas patologias adquiridas e transpassadas por meio dos nossos comportamentos sociais, contraditórios e dolorosos, que frequentemente assumimos para mantermos nossa existência material de caráter dialético. 

autoridade da estrutura do Estado Moderno seria cada vez mais desnecessária a partir da inversão e absorção dos valores humanitários de forma universal e democrática. 


\section{BIBLIOGRAFIA}

ALEMÀN, Gloria del Castillo y NEDULCE, Danay Quintana. Revista Mexicana de Sociologia 78, número 1(enero-marzo 2016): 7-32: México, D.F. ISSN: 0188-2503/16/07801-01.

BAMBIRRA, Vania. El capitalismo dependiente latino-americano. México: Sigilo XXI, 1974. Teoría de la dependencia: una anticrítica. México: Serie Popular Era, 2ª edición, 1983 [1978].

BOTELLO, Juan Idalbertto Ricardo; DELGADO, Eva Perón; POZO, Pedro Lino Del. La gestión estrategica de la cooperación internacional para el desarollo local en las condiciones de la economia cubana . In: Instituto Nacional de Investigaciones Económicas (INIE), n. 1 y 2 Enero - Diciembre, 2010, p. 15- 36 .

CABRAL, Domingos Savio de Azevedo. Doutrina Cooperativista. Disponível no Blog Cooperativismo e Ideias. Em

http://cooperativismoeideias.blogspot.com.br/2010/11/doutrina-cooperativista.html, acessado em Abril de 2018.

CARDOSO, F. H.; FALETTO, E. Dependência e Desenvolvimento na América Latina. In: BIELSCHOWSKY, R. (org.). Cinquenta anos de pensamento da CEPAL. Ed. Record, Rio de Janeiro, 2000 [1973].

DIERCCKXSENS, Wim. La transación hacia una nueva civilización. Casa Editora Abril, 2013.

DOS SANTOS, Theotonio. Imperialismo y Dependencia. Caracas: Biblioteca Ayacucho de Clásicos Políticos da América Latina; Banco Central de Venezuela, 2012.

. La crisis de la teoría del desarrollo y las relaciones de dependencia en América Latina. CESO, Universidad de Chile, No. 11, 1970.

FRANK, Andre Gunder. 0 desenvolvimento do subdesenvolvimento. Monthly Review, vol. 18, nำ 4, setembro de 1966. Artigo acessado em 03 de maio de 2019. Capitalismo y subdesarrollo en América Latina. Cuidad de México: Siglo XXI, 1970.

HARVEY, David. 17 contradições e o fim do capitalismo. Trad. Rogério Bettoni. 3 ed. - São Paulo, Boitempo, 2016.

HERNÁNDEZ, Rafael y RODRIGUEZ, Jorge. Cuba, la actualización del modelo: balance y perspectiva de la transición socialista. Ediciones Temas y David Rockefeller Center for Latin America Studies, La Habana - Washington DC, Diciembre, 2013.

LUCE, Mathias Seibel. Teoria Marxista da Dependência: problemas e categorias. Uma visão histórica. São Paulo: Expressão Popular, 2018.

MARINI, Rui Mauro. La dialética de la dependência. Ed. Siglo XXI, 1986. Subdesenvolvimento e revolução. Florianópolis: Insular, 2012.

MARX, Karl Heinrich e ENGELS, Friedrich. A Ideologia Alemã (Trad. Luis Claudio de Castro e Costa). São Paulo, Martins Fontes, 1998. Disponível em 
<http://www.usp.br/cje/anexos/pierre/aideologiaalema_karlmarx_e_engels.pdf>. Acessado em 30 de Julho de 2015.

Ministério da Agricultura, Pecuária e Abastecimento (MAPA). Evolução do cooperativismo no Brasil. 2006. Disponível em

http://www.dominiopublico.gov.br/download/texto/ac000001.pdf. Acessado em 27 de Dezembro de 2016.

Organização Internacional do Trabalho (OIT). COOPERATIVAS: Mudanças, Oportunidades e Desafios. 2001. Disponível em

http://www.oitbrasil.org.br/sites/default/files/topic/cooperative/pub/

cooperativas_mudancas_oportunidades_desafios_219.pdf. Acessado em 27 de Dezembro de 2016.

Organização das Nações Unidas (ONU), Comissão econômica para América Latina e Caribe (CEPAL), Programa das Nações Unidas para o Desenvolvimento (PNUD) e Instituto de Nacional Investigações Econômicas (INIE). Política Social y Reformas Estructurales: Cuba a princípios del siglo XXI, 2004. Disponível em http://repositorio.cepal.org/bitstream/handle/11362/25672/1/ S2004089_es.pdf. Acessado em 20 de janeiro de 2017.

PEISO, Avelino Fernádez. La Cooperativa: Bases para su legislación en Cuba. Editorial de Ciencias Sociales, 2012, Havana - Cuba.

QUINTIÁN, Saray Velázquez y RODRIGUEZ, Seida Barrera. Una mirada com enfoque de género a la legislación y la realidad de una cooperativa no agropecuaria cubana. Revista Idelcoop n. 218, marzo de 2016. ISSN 0327 1919, p. 79 -92 - Sección Reflexiones y Debates. Disponível em https:// www.idelcoop.org.ar/revista/218/una-mirada-enfoque-genero-legislacion-y-realidad-unacooperativa-no-agropecuaria-cubana. Acessado em 29 de dezembro de 2016.

SOUSA, Letícia Pulcides de. Cooperativismo: conceitos e desafios à implantação da economia solidária. Vitrine da Cojuntura, Curutiba, v.2, n.2, abril 2009. Disponível em img.fae.edu/galeria/ getImage/1/732687471628267.pdf . Acessado em Abril de 2018.

VILPOUX, Olivier F.; OLIVEIRA, Eule José de. Instituições informais e governanças em arranjos produtivos locais. Revista Quadrimestral do Instituto de Economia da Universidade Federal do Rio de Janeiro, vol 14, n. 1, jan.- abr. de 2010, p. 85-111.

VUOTTO, Mirta. Las cooperativas no agropecuárias y la transformación económica em Cuba: políticas, procesos y estrategias. REVESCO - Revista de Estudos cooperativos, 2015, p. 149-181. Disponível em:

https://revistas.ucm.es/index.php/REVE/article/view/49697/46198. Acessado em 23 de Dezembro de 2016.

WONG, Ángel Bu; RODRÍGUEZ, Guillermo Betancourt; GUITIÉRREZ, Roger Herrera; TORRES, Mónica Mireles; LEYV, Norisbel Arronte. Cooperativismo: una fortaleza dentro de la actualización del modelo económico cubano. In: Idem, p. 37-58.

\section{NOTAS}

1. MINISTÉRIO DA AGRICULTURA, PECUÁRIA e ABASTECIMENTO (MAPA), 2006, p. 10. Disponível em http://www.dominiopublico.gov.br/download/texto/ac000001.pdf. Acessado em 27 de Dezembro de 2016. 
2. Dados de acordo com o site http://cooperativismodecredito.coop.br/cooperativismo/ historia-do-cooperativismo/aci-alianca-cooperativa-internacional/. Acesso em $27 \mathrm{de}$ Fevereiro de 2018.

3. Informações retiradas do site Geração Cooperação (http://geracaocooperacao.com.br/ entenda-os-principios-do-cooperativismo/) Acessado em 18 de Abril de 2018.

4. Cultura e Educação são elementos flúidos, relativamente autônomos à nível popular, no que diz respeito à suas formas de manifestação. Porém, são também, elementos estruturais e instrumentos estatais para criação de consenso e submissão à ordem hegemônica capitalista por meio das políticas públicas, ou seja como Aparelhos Ideológicos do Estado (ALTHUSSER, 1970).

5. https://www.bbc.com/portuguese/brasil-39775504, acessado em 23 de junho de 2018.

\section{RESUMOS}

Este artigo propõe uma reflexão a partir da compreensão das contradições impostas pelo modo de produção capitalista às dimensões do desenvolvimento humano e da humanidade e da observação de políticas públicas latino americanas de cooperativismo, que tem como resultado indicativos de desenvolvimento alternativo ao sistema hegemônico atual. Durante a pesquisa sobre as políticas públicas de cooperativismo agrícola dos casos selecionados [Cuba e Brasil (MST)], outra gama de obstáculos que participam do processo de transição socialista se revela e confirma, ainda assim, a importância de políticas públicas a favor de práticas humanistas para reabilitação positivadas relações sociais entre indivíduos e para com a natureza.

Cet article propose une réflexion à partir de la compréhension des contradictions imposées par le mode de production capitaliste sur les dimensions du développement humain et de l'humanité et de l'observation des politiques publiques de coopérativisme en Amérique latine, qui aboutit à un dèveloppement alternatif au système hégémonique actuel. Lors de la recherche sur les politiques publiques de coopérativisme agricole des cas sélectionnés [Cuba et le Brésil (MST)], une autre série d'obstacles participant au processus de transition socialiste est révélée et confirme néanmoins l'importance des politiques publiques en faveur des pratiques humanistes pour la réhabilitation positive des relations sociales entre les individus et envers la nature.

Este artículo propone una reflexión a partir de la comprensión de las contradicciones impuestas por el modo de producción capitalista a las dimensiones del desarrollo humano y de la humanidad y de la observación de políticas públicas latinoamericanas de cooperativismo que tienen como resultado indicativos de desarrollo alternativo al sistema hegemónico actual. Durante la investigación sobre las políticas públicas de cooperativismo agrícola de los casos seleccionados [Cuba y Brasil (MST)], otra gama de obstáculos que participan en el proceso de transición socialista se revela y confirma, aún, la importancia de políticas públicas a favor de prácticas humanistas para rehabilitar positivadas relaciones sociales entre individuos y para con la naturaleza.

This article proposes a reflection from the understanding of the contradictions imposed by the capitalist mode of production on the dimensions of human development and humanity and the observation of Latin American public policies of cooperativism, which results in an alternative 
development to the current hegemonic system. During the research on the public policies of agricultural cooperativism of the selected cases [Cuba and Brazil (MST)], another range of obstacles that participate in the process of socialist transition is revealed and confirms, nevertheless, the importance of public policies in favor of practices humanists for positive rehabilitation social relations between individuals and towards nature.

\section{ÍNDICE}

Mots-clés: capitalisme, développement, coopérativisme, politique publique

Palabras claves: capitalismo, desarrollo, cooperativismo, políticas públicas

Keywords: capitalism, development, cooperativism, public policies

Palavras-chave: capitalismo, desenvolvimento, cooperativismo, políticas públicas

AUTOR

\section{GABRIELA ALVARENGA PRESTES}

Pesquisadora e doutoranda em Políticas Públicas e Formação Humana PPFH/UERJ com o tema

"Políticas públicas de desenvolvimento para o fim do capitalismo";

Mestre em Administração na UFF; Especialista em Políticas Públicas e Estratégias de

Desenvolvimento CE/UFRJ; Graduada em Produção Cultural UFF.

E-mail: galvarengaprestes@gmail.com 